\title{
As estratégias e os inúmeros desafios dos administradores de shoppings
}

\author{
Tiago Eloy Zaidan \\ Mestre em Comunicação Social \\ Universidade Federal de Pernambuco (UFPE) - Brasil \\ eloyzaidan@gmail.com
}

\section{REFERÊNCIA}

UNDERHILL, Paco. A magia dos shoppings: como os shoppings atraem e seduzem. Trad. Ana Beatriz Rodrigues. Rio de Janeiro: Elsevier, 2004. 253 p.

\section{CREDENCIAIS DO AUTOR DO LIVRO}

Paco Underhill, geógrafo urbano, antropólogo do varejo e psicológo comportamental norte-americano, é fundador da consultoria para o varejo Envirosell, a qual estuda aspectos relacionados à antropologia do consumo. O êxito vanguardista de sua consultoria o fez ser considerado um dos vanguardistas do que vem se chamando de ciência das compras. Outras das obras importantes do autor, publicadas no Brasil, são: Vamos às compras: a ciência do consumo nos mercados globais (Elsevier) e $O$ que as mulheres querem? (Elsevier), ambos com foco no comportamento do consumidor em ambientes de varejo.

\section{RESENHA CRÍTICA}

Ainda é cedo e as lojas não abriram. Mesmo assim, os corredores de um típico shopping de subúrbio, nos Estados Unidos, já estão cheios. São idosos com roupas confortáveis e calçados com sola de borracha. Estão fazendo exercícios cardiovasculares. Em outras palavras, estão caminhando. Muitos deles, por indicação médica. Acorrem aos corredores dos shoppings, sobretudo, para fugir das intempéries climáticas. Tal modalidade já tem até nome. Chama-se mall-walking.

Sem conseguir divisar claramente benefícios financeiros com a prática, alguns estabelecimentos passaram a obstruir as visitas matinais. Os administradores queixavam-se que, antes mesmo de o shopping abrir, o piso recém-encerado já estava sujo e as melhores vagas de estacionamento já estavam ocupadas. Em algumas comunidades, os "atletas" expurgados chegaram a se mobilizar, conseguindo com que o shopping voltasse atrás em suas medidas restritivas (UNDERHILL, 2004, p. 48-49).

Este caso ilustra a relação dos norte-americanos com os shoppings. Visto como algo fútil por alguns, mas amado por outros tantos, o fato é que estes templos do consumo concentram $14 \%$ do comércio varejista dos Estados Unidos, excluindo-se a venda de automóveis e de gasolina (UNDERHILL, 2004, p. 31). Quanto aos idosos, não é difícil entender porque o shopping é o local escolhido para a prática da caminhada. Abrigados da neve, dos motoristas ensandecidos - e seus carros poluidores - e sob um piso homogêneo - melhor que as calçadas repletas de armadilhas do mundo exterior (UNDERHILL, 2004, p. 60-61) - os membros da terceira idade se sentem mais seguros.

É justamente este o espaço ao qual se dedica Paco Underhill em seu A magia dos shoppings: como 
os shoppings atraem e seduzem. $\mathrm{O}$ autor fala com a autoridade de quem conhece mais de 300 shoppings nos Estados Unidos e no mundo (UNDERHILL, 2004, p.24). Mas não só. Underhill é também o fundador da empresa de consultoria Envirosell, a qual se especializou em estudar o comportamento dos consumidores nos ambientes de varejo. Seu trabalho na Envirosell o tornou referência no que vem se chamando de antropologia das compras.

Segundo explica o autor, em outro de seu livro (Vamos às compras!: a ciência do consumo nos mercados globais), a antropologia das compras abrange, dentre os seus objetivos e problemas:

Como criar cartazes que as pessoas leiam. Como se assegurar de que todas as mensagens estejam no local apropriado. Como criar mostruários que o shoppers possam manipular com facilidade e conforto. Como assegurar que os shoppers percorram - e desejem percorrer - todos os cantos da loja (UNDERHILL, 2009, p. 28).

Embora o estudioso do varejo não se atenha a questões epistemológicas em nenhum de seus livros, a pesquisa baseia-se, cientificamente, nas contribuições da etnografia, método marcante da antropologia social a qual não prescinde do fieldwork, a pesquisa de campo. Se o pesquisador polonês naturalizado britânico, Bronislaw Malinowski (1884-1942), foi a campo observar de perto os nativos de Trobriand, na Oceania, na década de 1920 (JAIME JR., 2001, p. 70), o que faz a antropologia do consumo é observar os compradores em seu habitat: o ambiente de compras.

Outra referência metodológica cara a Underhill é o historiador francês Daniel Roche, autor de A história das coisas banais, o qual se debruçou sobre o cotidiano de pessoas normais, os anônimos da França dos séculos XVII e XVIII (UNDERHILL, 2004, p. 25). Na linha de Roche, o foco de $A$ magia dos shoppings são os consumidores em suas atividades comezinhas dentro de um shopping. Assim, não espere do livro nenhuma menção a grandes empreendedores do ramo ou detalhes de cases emblemáticos construídos por algum magnata do varejo. Por outro lado, surgem insights e boas ideias, gestadas a partir da observação de pessoas comuns nos ambientes de compra.

E, nesta empreitada, um dos recursos utilizados é o desenho, sobre o mapa do estabelecimento, do caminho percorrido pelos compradores em uma incursão às lojas. Esta trilha mostra o quanto um estabelecimento estruturalmente ineficiente deixa os seus clientes perdidos ao tentar encontrar os produtos os quais desejam e os conduzem em direção à saída (UNDERHILL, 2004, p. 64-65). O norte-americano valeuse ainda de instrumentos como câmeras filmadoras - estrategicamente posicionadas, de modo a não serem localizadas - e gravador de áudio, com o qual gravou conversas com consumidores de segmentos demográficos distintos durante visitas ao mall.

A estrutura do livro, aliás, assemelha-se a um passeio pelo shopping, literalmente. A começar pela aproximação do centro de compras, a partir da rodovia, e pelo estacionamento. Já aqui, no local de guardar os carros - uma paixão dos estadunidenses - Underhill elenca desafios a serem vencidos pelas administradoras. Os estacionamentos dos malls são áridos, "sem graça" e, em muitos casos, sequer possuem calçadas (UNDERHILL, 2004, p. 36).

A bem da verdade, os problemas começam antes das grades do shopping. Ao contrário dos centros de compras japoneses e europeus - e, porque não, brasileiros - os estabelecimentos norte-americanos esnobam o transporte público. Nem mesmo as bicicletas são contempladas, pois não há bicicletários. Há shoppings que chegam ao ponto de proibir parada de ônibus em suas dependências. A lógica é perversa: "'Se você não tem um carro para chegar até aqui', eles parecem dizer, 'é melhor que não venha"' (UNDERHILL, 2004, p. 51). A segregação da falta de acesso faz sentido para os administradores, os quais se dizem preocupados com a visita de "baderneiros", os quais, seguindo a linha de raciocínio, seriam os jovens urbanos não-motorizados (UNDERHILL, 2004, p. 52).

No Brasil, especialmente com a ascensão do poder de consumo das classes mais vulneráveis, jovens da periferia representam uma parcela importante dos consumidores de shoppings, e, em regra, assim são vistos pelos administradores. Ainda assim, segundo pesquisa do Datafolha, publicada em janeiro de 2014, $82 \%$ dos paulistanos se declararam contrários aos chamados 'rolezinhos' - encontros os quais, a princípio, são organizados para reunir jovens em shoppings para fins de recreação; $73 \%$ dos entrevistados foram além, 
e se disseram a favor da repressão dos 'rolezinhos' pela Polícia Militar (DATAFOLHA, 2014).

Uma vez dentro do shopping, aspecto que incomoda Paco Underhill são as vitrines. A começar pela própria arquitetura, a qual nivela os mostruários conferindo às fachadas das lojas uma monotonia que em nada contribui para estimular os passantes. Postando-se rente a um mostruário e olhando-se para frente, é possível vislumbrar, tangencialmente, uma reta de fachadas de vidros as quais nada revelam a respeito das mercadorias que repousam poucos centímetros ao lado (UNDERHILL, 2004, p. 219).

Mesmo que se olhasse frontalmente, as vitrines - em um contexto de subutilização - não contribuiriam muito. Tem imperado a lógica de que o interior da loja deve ter a sua exposição maximizada para aqueles que passam no corredor em frente. A hegemonia das "paredes" de vidro não é por acaso. Portanto, a mediação de um mostruário funcionaria mais como um obstrutor (UNDERHILL, 2004, p. 164). Por seus turnos, as lojas grandes, as quais não prescindem das vitrines, têm subutilizado este recurso ao adotar projetos padronizados impostos por profissionais sediados em um escritório central, pouco levando em consideração o contexto de cada loja (UNDERHILL, 2004, p. 163).

No interior das lojas, o problema apontado pelo autor de A magia dos shoppings é o excesso de mercadorias expostas. Com o metro quadrado valorizado dos shoppings, procura-se aproveitar o espaço à exaustão. Entre disponibilizar cancha para o estoque e mercadorias no salão de compras, os varejistas optam por entulhar seus expositores. O resultado: nos departamentos de vestuário feminino, os cabides ocupados ficam tão imprensados que chega a ser difícil retirar uma roupa. Além disso, quem passa vislumbra pouco mais do que a manga de cada peça, única parte do vestuário à venda que consegue se projetar ante a visão do cliente (UNDERHILL, 2004, p. 211-213).

O excesso de mercadorias é prejudicial, sobretudo, aos portadores de deficiência física. Sem espaço entre balcões, araras e prateleiras, o tráfego de cadeiras de rodas torna-se inviável, a despeito do decreto legislativo que vigora nos Estados Unidos desde 1990, conhecido por American with Disabilities Act (UNDERHILL, 2004, p. 214). Apesar do amparo legal, o autor - um notório entusiasta no liberalismo - relativiza a insatisfação, por vezes litigiosa, dos cadeirantes: “[...] levar essa questão à justiça contradiz o preceito fundamental do mercado livre que reza o seguinte: os ofendidos que façam suas compras em outro lugar" (UNDERHILL, 2004, p. 214). E assim, talvez sem perceber, os shoppings restringem o acesso a mais um segmento da população.

Se, por um lado, alguns não se sentem contemplados, por outro, há - dentro de um shopping - quem pareça estar em seu habitat natural. Segundo Underhill, com a licença dos estereótipos, este é o caso das mulheres. Pelo menos em comparação aos homens. Trata-se de uma constatação relativa a uma média, evidentemente. Especialmente os homens mais velhos são menos afeitos aos malls. "O shopping destinase às compras como atividade em si, algo que a maior parte dos homens ainda precisa aprender a gostar" (UNDERHILL, 2004, p.155). Uma ilustração foi identificada nas filmagens da pesquisa de campo realizada em um setor de roupa masculina.

(...) [Os homens] encontram uma calça que seja do mesmo tamanho da que estiverem vestindo e se dirigem diretamente à caixa, sem olhar as outras mercadorias ou experimentálas. Passam na seção praticamente o mesmo tempo que dedicam à compra de cerveja em uma loja de conveniência (UNDERHILL, 2004, p. 156).

Em determinados momentos, a presença dos homens chega a ser um problema para o shopping. $\mathrm{O}$ que fazer com os maridos, namorados ou pais entediados enquanto as mulheres fazem compras? Acomodar a companhia do sexo masculino pode ajudar as vendas das lojas, embora estas não pareçam se preocupar muito com isso (UNDERHILL, 2004, p. 159).

Não é por acaso que boa parte do portfólio dos shoppings seja destinada às mulheres. No bojo, os cosméticos são notadamente importantes, dadas as altas margens de lucro que permeiam o setor (UNDERHILL, 2004, p. 77). Apesar disso, a arquitetura dos shoppings falha ao não atentar para um detalhe: embora as mulheres frequentem mais os banheiros e passem mais tempo neles, há, nos estabelecimentos, uma austera simetria na quantidade de toaletes masculinos e femininos. $O$ resultado, não raro, são as eventuais filas no banheiro das mulheres (UNDERHILL, 2004, p. 96).

É bom que se diga: nem tudo são flores na relação entre as mulheres e os shoppings. As mulheres estão 
mais ocupadas do que nunca (UNDERHILL, 2004, p. 244). A consequência óbvia disso: sobra menos tempo para frequentar os malls. Na realidade, falta de tempo é um problema geral. Por isso, o varejo, um setor dinâmico, tem ocupado espaços como aeroportos, os quais hoje em dia se assemelham a shoppings. A ideia é aproveitar o tempo das pessoas onde quer que elas estejam (UNDERHILL, 2004, p. 241).

Tem ocorrido ainda uma mudança cultural. Segundo aponta Underhill, "hoje, boa parte da poupança da classe média americana destina-se a viagens e aventuras, bens intangíveis que enriquecem o espírito muito mais que a conta bancária de um Ralph Lauren, por exemplo" (UNDERHILL, 2004, p. 240). O autor cita ainda um problema que está na essência do setor. O fato de que os shoppings são empreitadas capitaneadas pelo setor imobiliário, muito menos habilidoso que empresários do varejo, estes, mais habituados a lidar com as vicissitudes dos consumidores finais (UNDERHILL, 2004, p. 236). No Brasil, algumas das redes mais bem-sucedidas de shoppings são iniciativas de empreendedores com larga experiência no varejo. Isso pode explicar o sucesso de malls como a bandeira nordestina Rio Mar, fundada pelo ex-dono da rede de supermercados Bompreço, na esteira propiciada pela redução das disparidades regionais no país e pelo crescimento econômico do Nordeste.

O fato é: por um motivo ou outro, nos Estados Unidos, as pessoas parecem estar se saturando de shoppings, o que se reflete na drástica redução da construção de novos empreendimentos, em contraste com o pulular de malls verificados nos anos 1970 e 1980 (UNDERHILL, 2004, p. 235-236). Nem mesmo um entusiasta das compras, como o é Paco Underhill - o qual acredita que o consumo nos ensina a "conviver com as diferenças" (UNDERHILL, 2004, p .221) -, demonstra complacência. Para o autor de A magia dos shoppings, o objeto de estudo de seu livro "Poderia ser um lugar muito melhor - mais intenso, inteligente, surpreendente, divertido, criativo, repleto da busca humana da arte, beleza e verdade. Mas não é. É o shopping" (UNDERHILL, 2004, p 21).

\section{REFERÊNCIAS}

DATAFOLHA. 82\% dos paulistanos são contra rolezinhos em shoppings. São Paulo, 23 de jan. 2014. Disponível em: <http://datafolha.folha.uol.com.br/opiniaopublica/2014/01/1401676-82-dos-paulistanossao-contra-rolezinhos-em-shoppings.shtml>. Acesso em 20 ago. 2015.

UNDERHILL, Paco. Vamos às compras!: a ciência do consumo nos mercados globais. Trad. Ricardo Bastos Vieira. Rio de Janeiro: Elsevier, 2009. 317 p.

JAIME JR., Pedro. Etnomarketing: antropologia, cultura e consumo. RAE - Revista de Administração de Empresas, São Paulo, v. 41, n. 4, p. 68-77, out./dez. 2001. Disponível em: <http://www.scielo.br/pdf/rae/ v41n4/v41n4a08>. Acesso em: 23 mar. 2015. 